\title{
NUTRITION OF THE EUROPEAN CORN BORER, PYRAUSTA NUBILALIS (HBN.)
}

\author{
III. An Unidentified Dietary Factor RequiRed for Larval Growth* \\ By STANLEY D. BECK \\ (From the Department of Entomology, College of Agriculture, University \\ of Wisconsin, Madison)
}

(Received for publication, July 7, 1952)

As part of an investigation of the relationships between the European corn borer and its principal host plant, the insect's nutritional requirements are being studied. The possible role of nutritional factors in the phenomena of host selection, host plant resistance, and the orientation of the insect on the host plant at different stages in the life cycle of both plant and insect has yet to be determined for any phytophagous insect. One of the first requirements of such studies is a knowledge of the basic nutritional needs of the insect.

In the first paper of this series (Beck et al., 1949) it was reported that mixtures of crystalline $B$ vitamins incorporated into a purified diet failed to allow normal growth and development of European corn borer larvae. Growth on the purified diet was improved by the addition of 10 per cent brewer's yeast powder, but the incorporation of corn leaf tissue was necessary for optimal larval growth. The factor, or factors, contained in the dried corn leaves which contributed so greatly to larval growth and maturation was termed the "corn leaf factor."

The isolation and identification of the corn leaf factor are of considerable importance to any continued study of the nutrition of the borer. This is true because the study of the insect's requirements for other dietary constituents will be on uncertain ground as long as crude materials of unknown composition must be added to the diet in order to obtain normal growth. The identification of this factor is also of interest from an academic standpoint in that it may represent a fundamental departure from the nutritional requirements of the more thoroughly studied insects found in cereal products. The first step in the quantitative determination of the nutritional requirements of the borer larvae is, therefore, the elucidation of unknown factors and the replacement of crude products with purified or crystalline compounds.

* Approved for publication by the Director of the Wisconsin Agricultural Experiment Station. This investigation was supported in part by the Research Committee of the Graduate School from funds supplied by the Wisconsin Alumni Research Foundation. 
TABLE I

Composition of the Basal Purified Diet Used in Nutritional Studies on the European Corn Borer

\begin{tabular}{|c|c|c|c|}
\hline Function & Substance & Amount used & Dry diet \\
\hline \multirow{4}{*}{ Carrier } & & sm. & per cent \\
\hline & Distilled water & $125.00(\mathrm{ml})$. & 0.0 \\
\hline & Bacto-agar & 3.350 & 14.5 \\
\hline & Cellulose (fibrous) & 2.750 & 12.0 \\
\hline Carbohydrate & Glucose & 7.600 & 33.0 \\
\hline Protein & Casein* & 6.400 & 27.8 \\
\hline \multirow[t]{2}{*}{ Lipids } & Cholesterol & 0.230 & 1.0 \\
\hline & $\begin{array}{l}\text { Corn oil containing } 1 \text { per cent } \\
\text { tocopherol }\end{array}$ & 0.230 & 1.0 \\
\hline Minerals & Wesson's salt $\ddagger$ & 0.460 & 2.0 \\
\hline \multirow[t]{2}{*}{ Vitamins } & Vitamin B complex (Table II) & 0.075 & 0.4 \\
\hline & Choline chloride & 0.065 & 0.3 \\
\hline \multirow[t]{2}{*}{ Unknown factor(s) } & Leaf sap concentrate $\S$ & 1.840 & 8.0 \\
\hline & & $\overline{23.000}$ & $\overline{100.0}$ \\
\hline
\end{tabular}

" "Vitamin test" casein, General Biochemicals, Inc.

$\ddagger$ Nutritional Biochemicals, Inc.

8 "SBJ" grass leaf fraction supplied by Cerophyl Laboratories, Inc. This concentrate replaced the dried corn leaves used in earlier work.

\section{TABLE II}

$B$ Vitamins Used in Nutritional Studies on the European Corn Borer

\begin{tabular}{|c|c|}
\hline Vitamin & $\begin{array}{c}\text { Amount, per gm. } \\
\text { dry weight }\end{array}$ \\
\hline Choline chloride... & $\begin{array}{c}\mu g . \\
1000\end{array}$ \\
\hline Thiamine $\mathrm{HCl} . . .$. & 12 \\
\hline Riboflavin........ & 18 \\
\hline Nicotinic acid....... & 100 \\
\hline $\mathrm{Ca}$ pantothenate ............ & 40 \\
\hline Pyridoxine $\mathrm{HCl} . \ldots \ldots \ldots \ldots \ldots \ldots \ldots \ldots \ldots \ldots \ldots \ldots \ldots$ & 16 \\
\hline 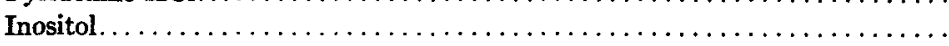 & 2000 \\
\hline 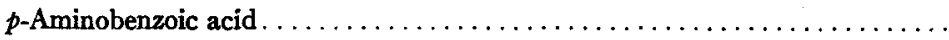 & 50 \\
\hline 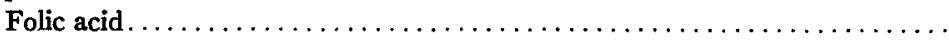 & 5 \\
\hline Biotin.$\ldots \ldots \ldots \ldots \ldots \ldots \ldots \ldots \ldots \ldots \ldots \ldots \ldots \ldots \ldots \ldots \ldots$ & 1 \\
\hline
\end{tabular}




\section{Material and Methods}

The basal diet employed in this study was an agar-based culturing medium. Its composition is presented in Table I. This diet is slightly modified from that used in earlier work (Beck, 1950). The vitamin mixture employed is shown in Table II. This mixture was used in earlier work (Beck et al., 1949), and is essentially that used by Noland et al. (1949) in nutrition studies on the German cockroach, Blattella germanica (L.). It is similar in composition but approximately twice as concentrated as that employed by Lepp et al. (1947) in studies on chick nutrition. Halving or doubling the amounts of vitamins in the mixture had little or no effect on larval growth and development; so it has been assumed that the level of each vitamin is within the optimal range for the European corn borer.

Although originally discovered in leaves of the corn plant, corn leaf factor activity has been found in other plant materials, as is discussed in a later section. The assay of different plant materials for corn leaf factor activity led to the adoption of a grass leaf concentrate as the standard source of the factor. This concentrate not only showed very high activity, but also was available in quantity and contained no fibrous material which might alter the physical characteristics of the basal diet.

The methods used in preparing the media and maintaining the cultures have been described in detail elsewhere (Beck and Stauffer, 1950), and need be only summarized here. Egg masses of the European corn borer were separated by incubating them in dilute trypsin solution buffered at $\mathrm{pH}$ 8.0. The single eggs so obtained were rinsed thoroughly, were surface-sterilized in a solution containing 2 per cent sodium hydroxide and 2 per cent formaldehyde, and were introduced into sterile shell vials containing the dietary media. Twenty-five eggs, each in a separate rearing vial, were started on each diet. Rearing was carried out at $30^{\circ} \mathrm{C}$. The larvae grew rapidly on the basal diet, and matured in from 15 to 21 days. Any vials that became contaminated with microorganisms during incubation were discarded. At the end of 21 days the vials were opened, the pupae and larvae were weighed, and the puape were set aside for adult emergence. Adults emerging from pupae obtained on the basal diet appeared to be normal and produced fertile eggs. Several generations have been reared on the basal diet with no apparent loss of vitality. In spite of the apparent satisfactory nature of the basal diet, eggs from field-collected borers were employed in all experiments reported here in order to avoid the use of insects which might deviate signifcantly from the natural wild population.

\section{RESULTS}

Corn Leaf Factor Requirement.-The data shown in Table III clearly demonstrate that there are one or more unidentified dietary factors required for normal growth and maturation of the European corn borer. These data show that yeast powder, leaf concentrate, and the vitamin mixture (Table II) were each inadequate alone. The yeast powder alone allowed better growth than either of the others alone, however. Only leaf concentrate plus yeast or vitamin mixture allowed normal growth. In the presence of the leaf concentrate, the yeast powder may be completely replaced by the vitamin mixture. These 
results demonstrate that the leaf concentrate is an adequate source of the one or more unidentified growth factors required by the borer larvae.

The corn leaf factor activity of different lots of leaf concentrate varied somewhat, making it necessary to determine the optimum dietary level for each lot. Therefore, any quantitative estimation of the larval requirement has little meaning except as an assay of the activity of the particular concentrate being employed. Certain features of the insect's requirement of the corn leaf factor are reasonably constant and are illustrated by the data shown in Fig. 1. These data indicate that the optimum corn leaf factor level was reached when the crude leaf concentrate constituted about 8 per cent of the diet. It is apparent from these results that although a dietary level of 4 per cent crude

TABLE III

Growth and Maturation of European Corn Borer Laroae on Diets Containing Different Sources of Vitamins

\begin{tabular}{|c|c|c|c|}
\hline \multirow{2}{*}{ Dietary source of vitamins } & \multicolumn{3}{|c|}{ Growth of larvae at 21 days } \\
\hline & $\begin{array}{c}\text { Average larval } \\
\text { weight }\end{array}$ & $\begin{array}{c}\text { Average pupal } \\
\text { weight }\end{array}$ & $\begin{array}{c}\text { Per cent } \\
\text { mature }\end{array}$ \\
\hline & mg. & mg. & \\
\hline Leaf concentrate plus vitamin mixture (basal). & 65.4 & 94.1 & 83.3 \\
\hline Yeast powder only $\ldots \ldots \ldots \ldots \ldots \ldots \ldots \ldots$ & 22.1 & 43.0 & 31.2 \\
\hline Leaf concentrate only $\ldots \ldots \ldots \ldots \ldots$ & 21.1 & - & 0.0 \\
\hline Vitamin mixture only.. & 15.6 & - & 0.0 \\
\hline Yeast powder plus vitamin mixture.... & 22.6 & 47.5 & 17.6 \\
\hline Leaf concentrate plus yeast powder. . & 80.3 & 77.3 & 82.6 \\
\hline
\end{tabular}

leaf concentrate allowed the best weight gain and per cent reaching pupation, the optimum for the emergence of normal female moths was higher and approached 8 per cent. It is also strikingly apparent that the females required a much higher level of corn leaf factor than did the males. Moths were classified as subnormal if they exhibited any of the following deficiency symptoms: (1) failure to escape from the pupal case; (2) failure of the wings to expand; and (3) failure to live more than 1 or 2 days. Borers on diets containing 8 or more per cent leaf concentrate were normal in appearance and activity and laid fertile eggs which gave rise to viable larvae. Dietary levels of leaf concentrate greater than 8 per cent tended to inhibit borer development; this phenomenon may have been due largely to the presence of toxic materials in the leaf concentrate, rather than to a narrow optimal range of corn leaf factor concentration. In subsequent purification procedures it was found that some fractions of the crude concentrate inhibited borer growth.

Thus far it has not been possible to devise a satisfactory arbitrary unit with which to express corn leaf factor activity of different crude and purified prep- 


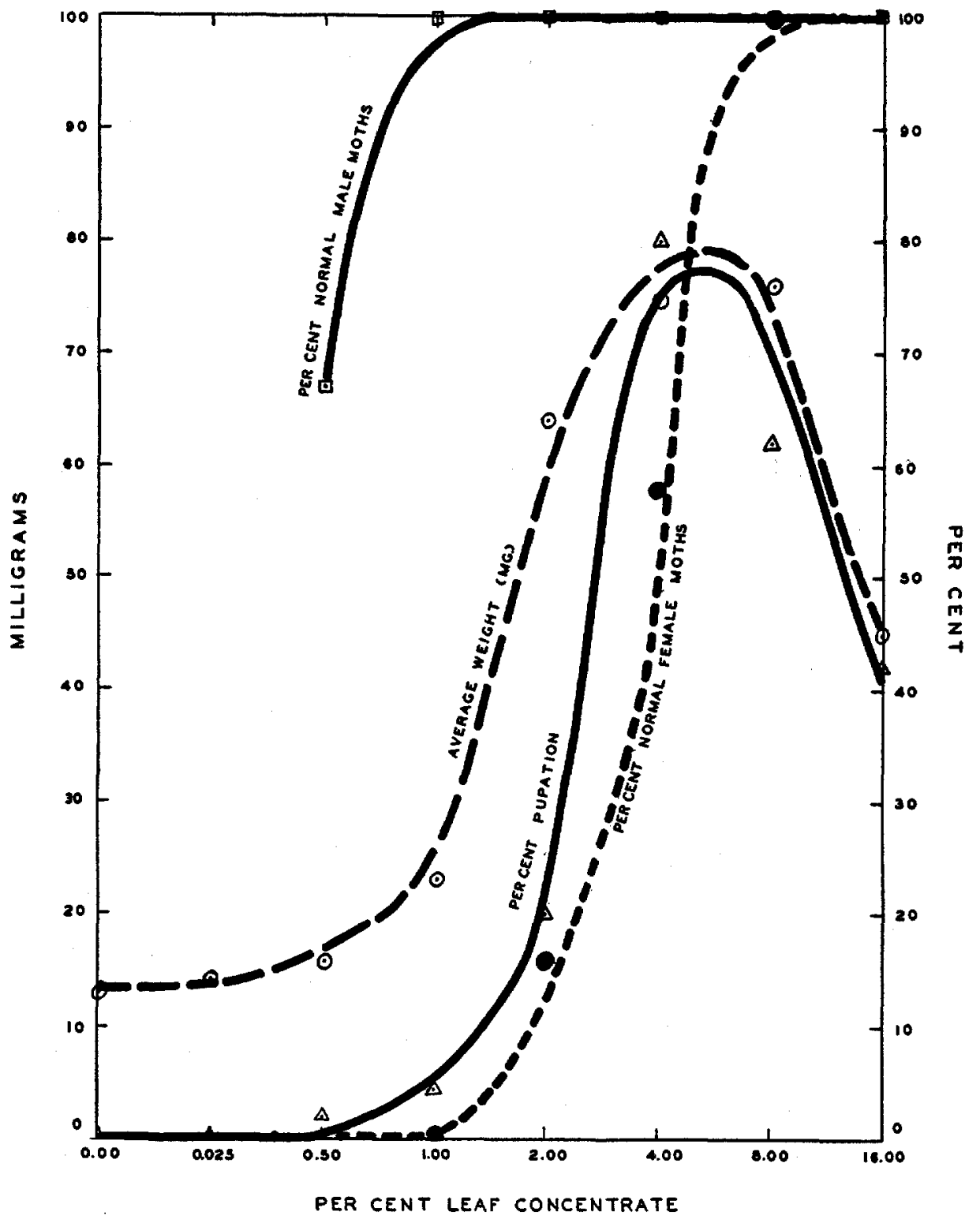

Fig. 1. Growth and maturation of European corn borer larvae on diets containing different amounts of corn leaf factor concentrate. 
arations. Since no single criterion of dietary adequacy has given a reliable estimate of corn leaf factor activity, the average weight at 21 days, the per cent reaching pupation within 21 days, and the apparent normalcy of the adult moths have all been used in estimating corn leaf factor activity. These three criteria do not appear to be sufficiently closely related to enable one to devise a system of activity units in which all three are taken into account. Although the data of Fig. 1 indicate a very close correlation between average weight and per cent pupation, it has been found that these two phenomena are not necessarily closely correlated. Brewer's yeast powder evidently contains some corn leaf factor activity, but dietary inclusion of large amounts of yeast powder did not lead to optimal growth. The data in Table IV are typical of an experiment in which different dietary levels of yeast powder were

TABLE IV

Growth and Maturation of European Corn Borer Larvae Fed for 21 Days on Diets Containing Different Amounts of Brewer's Yeast Powder as a Source of Vilamins

\begin{tabular}{|c|c|c|c|c|}
\hline \multirow{2}{*}{ Dietary yeast } & \multirow{2}{*}{ Average weight } & \multirow{2}{*}{ Pupation } & \multicolumn{2}{|c|}{ Normalcy of adults } \\
\hline & & & $0^{7}$ & ? \\
\hline per cent & mg. & per cent & per cent & per cont \\
\hline Control (basal) & 89 & 83 & 100 & 100 \\
\hline 0 & (No survival) & - & - & - \\
\hline 10 & 31 & 31 & 100 & 0 \\
\hline 20 & 39 & 38 & 100 & 0 \\
\hline 30 & 41 & 92 & 100 & 0 \\
\hline
\end{tabular}

fed in the absence of leaf concentrate and other vitamin sources. The data show that increasing the amount of yeast powder increased the percentage of pupation without an appreciable increase in either average weight or the incidence of normal female moths. Although the male moths were dwarfed, they were otherwise normal in appearance. These results suggest that there may be more than one unidentified growth factor in the leaf concentrate. This point however, cannot be established unless some chemical fractionation of the leaf concentrate results in a division of the apparent activity. No such division has been detected thus far in the purification procedure.

Natural Sources of Corn Leaf Factor.-A number of crude materials have been tested for corn leaf factor activity. Although the borer's natural food is parts of the corn plant, and the insect's requirement for the corn leaf factor was discovered when dried corn leaves were added to the purified diet, it was considered desirable to determine whether the corn leaf factor was unique to corn leaves or was of a more general distribution. Table $\mathrm{V}$ presents the results of assaying a number of crude materials for corn leaf factor activity. The dietary level of each was at a level expected to give suboptimal growth, in 
order that differences in relative corn leaf factor content might be detectable. These data indicate that several plant preparations showed corn leaf factor activity. The animal substances assayed contained little or no activity. The Cerophyl products were furnished by Cerophyl Laboratories, Inc., of Kansas City, Missouri, and were different grass extracts. Of them, only the fraction designated SBJ showed appreciable activity. This fraction was a juice that had been expressed from grass plants, boiled, filtered, and spray-dried. Be-

TABLE V

Growth of European Corn Borer Larvae Kept for 21 Days on Diets Containing Different Crude Materials as Sources of Corn Leaf Factor

\begin{tabular}{|c|c|c|c|c|c|}
\hline Substance tested & $\begin{array}{c}\text { Dietary } \\
\text { level }\end{array}$ & $\begin{array}{c}\text { Average } \\
\text { larval } \\
\text { weight }\end{array}$ & $\begin{array}{c}\text { Average } \\
\text { pupal } \\
\text { weight }\end{array}$ & $\begin{array}{l}\text { Maturation } \\
\text { (pupation or } \\
\text { diapause) }\end{array}$ & $\begin{array}{l}\text { Estimated } \\
\text { activity }\end{array}$ \\
\hline & per cent & mg. & mg. & per cont & \\
\hline None (negative control). & - & 19 & - & 0 & - \\
\hline Corn leaves.......... & 5 & 64 & 52 & 56 & $+t+t$ \\
\hline Corn tassels. . . . . . . . & 5 & 63 & 80 & 50 & $t+t+$ \\
\hline Corn silks............ & 5 & 18 & - & 0 & - \\
\hline Wheat germ................. & 5 & 55 & 63 & 13 & + \\
\hline Mixed pollen...$\ldots \ldots \ldots \ldots \ldots$ & 5 & 24 & 52 & 27 & $+t$ \\
\hline Brewer's yeast powder.......... & 5 & 21 & 53 & 40 & $+t$ \\
\hline Yeast extract................. & 2 & 16 & 55 & 47 & ++ \\
\hline Cerophyl $1 \ldots \ldots \ldots \ldots \ldots \ldots$ & 5 & 21 & - & 0 & - \\
\hline Cerophyl $7 \ldots \ldots \ldots \ldots \ldots$ & 5 & 35 & - & 0 & - \\
\hline Cerophyl 6J.............. & 5 & 40 & - & 0 & - \\
\hline Cerophyl SBJ $\ldots \ldots \ldots \ldots \ldots$ & 5 & 78 & 63 & 50 & $+t+t$ \\
\hline Dried liver $\ldots \ldots \ldots \ldots \ldots \ldots \ldots$ & 5 & 15 & - & 0 & - \\
\hline Liver concentrate.............. & 2 & 15 & 一 & 0 & - \\
\hline Liver " $L " \ldots \ldots \ldots \ldots \ldots \ldots \ldots$ & 2 & 7 & - & 0 & - \\
\hline Peptone (Parke Davis). & 5 & 28 & - & 0 & - \\
\hline
\end{tabular}

* An estimate based on the relative larval and pupal weight and the per cent maturation, in which ++++ represents the optimum growth factor response and indicates adequacy of the diet.

cause it was obtainable in large quantities, SBJ was used as the standard source of corn leaf factor in much of the subsequent work on the factor. Except for the original lot, the SBJ furnished by Cerophyl was a thick tarry concentrate rather than a dry powder. This material constituted the leaf concentrate referred to in this paper.

Of the three portions of the corn plant tested for corn leaf factor activity, only the silks were inactive. European corn borer larvae of the summer (August) generation are apt to invade the ear of the corn plant by travelling down the silks to the kernels, doing some feeding in the silk itself. A favorite site of borer feeding in the early summer is the tassel, the young borers in- 
vading this part of the plant before it has opened out. The tassel appeared to be an excellent source of the corn leaf factor in the experiments run.

Non-Identity of Corn Leaf Factor with B Vitamins and Other Factors.-The known $B$ vitamins, thiamine, riboflavin, pyridoxine, pantothenic acid, nicotinic acid, choline, inositol, para-aminobenzoic acid, biotin, folic acid, and $B_{12}$, have been tested individually for corn leaf factor activity with uniformly negative results. The finding of Shultz et al. (1946) that Drosophila requires nucleic acid components in its diet led to the testing of sodium nucleate and adenine for corn leaf factor activity, with negative results. Ascorbic acid, "citrovorum factor," 1 and carnitine ${ }^{2}$ have also shown no corn leaf factor activity. The results obtained from testing the known water-soluble vitamins

TABLE VI

Corn Leaf Factor Activity of Different Chemical Fractions of Leaf Concentrate

\begin{tabular}{|c|c|}
\hline Fraction of leaf concentrate tested & $\begin{array}{l}\text { Approximate } \\
\text { activity }\end{array}$ \\
\hline Unmodified concentrate......... & ++++ \\
\hline Ashed concentrate $\ldots \ldots \ldots \ldots \ldots \ldots \ldots \ldots \ldots$ & - \\
\hline Heat-coagulable fraction $\ldots \ldots \ldots \ldots \ldots \ldots \ldots \ldots$ & - \\
\hline Heat non-coagulable fraction $\ldots \ldots \ldots \ldots \ldots \ldots \ldots$ & $+t+t$ \\
\hline 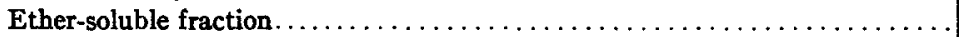 & - \\
\hline 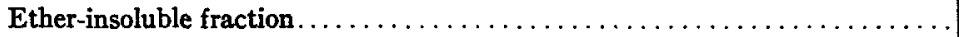 & ++++ \\
\hline 50 per cent acetone-insoluble fraction $\ldots \ldots \ldots \ldots \ldots \ldots \ldots$ & - \\
\hline 50 per cent acetone-soluble fraction . . . . . . . & $+t+t$ \\
\hline Charcoal filtrate ................... & +++ \\
\hline Dialyzable (water) fraction.$\ldots \ldots \ldots \ldots \ldots \ldots \ldots \ldots \ldots \ldots \ldots \ldots$ & $++t$ \\
\hline Non-dialyzable fraction.$\ldots \ldots \ldots \ldots \ldots \ldots \ldots \ldots \ldots \ldots \ldots \ldots \ldots \ldots \ldots \ldots$ & - \\
\hline
\end{tabular}

strongly indicate that the corn leaf factor is not identical with any of them. The possibility of its being an amino acid or some other well known nutrilite has not been completely eliminated by the experimental work carried out thus far.

Chemical Properties.-Chemical fractionation of the leaf concentrate in an effort to purify the corn leaf factor has been undertaken, and certain chemical properties are already apparent. The corn leaf factor is water-soluble, relatively heat- and acid-stable, non-adsorbable on charcoal (norit), and is dialyzable. The results obtained from assaying different chemical fractions of the leaf concentrate are presented in Table VI. The systematic fractionation of a sample through the steps shown in Table VI has yielded a concentrate in

${ }^{1}$ Supplied by Professor C. A. Baumann, Department of Biochemistry, University of Wisconsin.

${ }^{2}$ Purified $B_{t}$ supplied by Professor G. S. Fraenkel, Department of Entomology, University of Illinois. 
which recovery of total corn leaf factor activity was approximately 75 per cent, and the purification on the basis of apparent activity per milligram dry weight was about 20 times.

\section{SUMMARY}

1. The European corn borer larva has been shown to require a dietary source of one or more unidentified factors contained in corn leaves, grass juice concentrate, and certain other plant materials. The required factor or factors has been termed the corn leaf factor.

2. The corn leaf factor does not appear to be identical with any of the known B vitamins, or with ascorbic acid, sodium nucleate, citrovorum factor, or carnitine.

3. The corn leaf factor is heat-stable, acid-stable, water-soluble, and dialyzable.

\section{LITERATURE CITED}

1. Beck, S. D., 1950, Physiol. Zool., 23, 353.

2. Beck, S. D., Lilly, J. H., and Stauffer. J. F., 1949, Ann. Entomol. Soc. Am., 42, 483.

3. Beck, S. D., and Stauffer, J. F., 1950, J. Econ. Entomol., 43, 4.

4. Lepp, A., Moore, P. R., Elvehjem, C. A., and Hart, E. B., 1947, Poultry Sc., 26, 598.

5. Noland, J. L., Lilly, J. H., and Baumann, C. A., 1949, Ann. Entomol. Soc. Am., 42, 63.

6. Schultz, J., St. Lawrence, P., and Newmeyer, D., 1946, Anat. Rec., 96, 540. 